\title{
Barriers to Adherence to Iron Chelation Therapy in Thalassemia Patients
}

Tanuka Barua ${ }^{1 *}$

Golam Mohammed Tayab Ali ${ }^{2}$

Rana Chowdhury ${ }^{1}$

Dhananjoy Das ${ }^{1}$

Showrov Barua Chowdhury

Mahmud Ahmed Chowdhury Arzu

'Department of Paediatrics

Chattogram Maa-O-Shishu Hospital Medical College Chattogram, Bangladesh.

${ }^{2}$ Department of Paediatrics

Rangamati Medical College

Rangamati, Bangladesh.
*Correspondence to:

Dr. Tanuka Barua

Associate Prosessor

Department of Paediatrics

Chattogram Maa-O-Shishu Hospital Medical College

Chattogram, Bangladesh.

Mobile : +8801821654937

Email : tanukadr@gmail.com

Date of Submission : 22.04 .2021

Date of Acceptance : $\quad 30.05 .2021$

\begin{abstract}
Background: Thalassemias are the most common inheritable blood disorders requiring regular blood transfusions and iron chelating therapy. Non-adherence to iron chelation therapy increases complications and is a problem in treating thalassemia. To assess the reasons of non-adherence to iron chelating drug in treating thalassemia.

Materials and methods: This descriptive cross-sectional study was carried out in the thalassemia ward of Chattogram Maa Shishu-O-General Hospital, Chattogram from July, 2013 to June, 2014. 70 thalassemia patients aged 2-18 years previously treated with iron chelating drugs were included. Parents were interviewed according to a formulated questionnaire based on discontinuation of iron chelating drugs and its reasons. Data were analyzed by both manually and by SPSS-18.

Results: About $48.6 \%$ patients needed blood transfusion $>10$ units/year and $62.9 \%$ patients were prescribed with iron chelating drugs. Near about half patients (47.7\%) did not continued iron chelating therapy till full prescribed period. Deferiprone (31.8\%) and combination of deferipronc \& desferrioxamine (31.8\%) was the most commonly prescribed drug. Deferiprone is the drug to which most of the patients (70\%) were adherent and a good number of patients (65\%) discontinued desferrioxamine. Financial problem (100\%) was the only reason for discontinuation of oral chelator. In case of parenteral chelator, besides finanacial problem (38.5\%), time consuming natures (38.5\%), need of hospital admission (23\%) are the other causes for non-adherence to iron chelation therapy.
\end{abstract}

Conclusion: Financial problem is the main cause of non-adherence to iron chelation therapy. Iron chelating drugs should be available at low cost.

Key words: Iron chelating drugs; Non-adherence; Thalassemia.

\section{INTRODUCTION}

Thalassaemias are a heterogeneous group of genetic disorders of human haemoglobin synthesis, characterized by imbalanced globin chain production which leads to ineffective erythropoiesis and anaemia ${ }^{1}$. There are an estimated 270 million individuals worldwide who are carriers of globin gene mutations ${ }^{2}$. A conservative WHO report estimates that $3 \%$ of total population is carrier of $\beta$-thalassemia and $4 \%$ are carriers of $\mathrm{Hb} \mathrm{E}$ in Bangladesh and more than two thousand thalassemic children are born every year ${ }^{3,4}$.

The clinical picture of thalassemia major is characterized by growth retardation, pallor, jaundice, hepato-splenomegaly, skeletal changes that needs regular blood transfusion at 3-4 week interval to maintain $\mathrm{Hb}$ level of at least $9-10 \mathrm{mg} / \mathrm{dl}$ to improve growth and development, to reduce bone deformities and also to prevent hepato-splenomegaly due to extramedullary hematopoiesis ${ }^{5-9}$. Iron chelating drugs 
are needed as regular blood transfusion results in iron overload and related complication such as dilated cardiomyopathy, liver cirrhosis, endocrine problem and others ${ }^{10,11,12}$. Individuals who have not been regularly transfused usually die before $2^{\text {nd }}-3^{\text {rd }}$ decade $^{13,14}$. Survival of individuals who have been regularly transfused and treated with appropriate chelation extends beyond the age of 40 years $^{15}$. In a study of an Italian cohort reported that with optimal iron chelation therapy, $68 \%$ thalassemia patients lived to the age of 35 years ${ }^{16}$. In our country iron chelators in current clinical use are subcutaneous or intravenous desferrioxamine, oral deferiprone and oral deferasirox. Desferrioxamine is most commonly administered as a subcutaneous infusion over 8-10 hours, 3-6 nights weekly. But compliance with iron chelating therapy is a major issue. Compliance with iron chelating therapy mainly influences frequency and severity of the iron-overload related complication. In a substantial proportion of patients in routine clinical practice, adequate control of tissue iron levels is not achieved due to non-compliance and poor adherence to iron chelating therapy. Adherence is poor in majority of the patients for various reason including higher costs, discomfort, time consuming nature, unavailability, forgetfulness ${ }^{17}$. The adherence to treatment, the ease and satisfaction from their therapy differs according to type, route of administration of iron chelating drugs ${ }^{18}$. In a study in Australia the duration and discomfort of the infusion was the main issue for nonadherence to iron chelating therapy and higher adherence rates were identified for oral deferiprone, especially in patients with poor desferrioxamine adherence, suggesting that the mode of administration plays a major role ${ }^{19}$. In some countries, difficulty of access to iron chelating medications is a significant reason for non-compliance ${ }^{20}$. Wider availability of oral medications is likely to improve adherence and subsequent health outcomes. It is very common in some developing countries that patients are undertreated or irregularly transfused and poorly adherent to iron chelator due to lack of resources ${ }^{21}$. The barriers to adherence to iron chelation therapy in thalassemia patients have not been well studied in our country. We have conducted this study to address these barriers so that measures can be taken to overcome the barriers.

To assess the reasons of non-adherence to iron chelating drugs in treating thalassemia

\section{MATERIALS AND METHODS}

It was a descriptive cross-sectional study conducted at Chattogram Maa Shishu-O-General Hospital, Chattogram from July, 2013 to June, 2014. 70 thalassaemia patients aged 2-18 years previously treated with iron chelating drugs attending Thalassaemia Care Centre of Paediatric ward of Chattogram Maa Shishu-O-General Hospital, Chattogram with history of intake of iron chelation therapy were included. All newly diagnosed cases were excluded. After approval from the Ethical
Review Committee of Chattogram Maa Shishu-O-General Hospital, Chattogram, informed written consent was obtained from any of parents or a family member of each patient. Detailed study related information was read out and explained in the local language from a printed hand out. Parents were interviewed according to a formulated questionnaire asking the type of iron chelating drugs prescribed and reasons for discontinuation. Data were checked and analyzed manually with the help of calculator and software SPSS 18.0 according to the objective of the study. All aspects of confidentiality of participant were maintained and anyone was allowed to discontinue if he or she wanted.

\section{RESULTS}

Regarding treatment history, $25.7 \%$ needed blood transfusion less than 5 units/year, another $\quad 25.7 \%$ needed 5-10 units/year and nearly half patients (48.6\%) needed more than 10 units/year. About $62.9 \%$ patients were prescribed with iron chelation therapy. Of them, $31.8 \%$ patients were prescribed with DFN only, another $31.8 \%$ were prescribed with DFO \& DFN combination, $4.5 \%$ with alternate DFN \& DFX, $18.3 \%$ patients were prescribed with DFX only and $13.6 \%$ with DFO \& DFX combination. So most commonly prescribed iron chelation therapy was DFN single drug and DFO \& DFN coprescription. Splenectomy was done previously only in $5.7 \%$ patients but no one was able to afford bone marrow transplantation (Table I).

Table I : Patient's treatment profile $(\mathrm{n}=70)$

\begin{tabular}{lrc} 
Treatment Profile & Frequency & Percentage (\%) \\
Need blood transfusion & & \\
$<5$ times/year & 18 & 25.7 \\
$5-10$ times/year & 18 & 25.7 \\
$>10$ times/year & 34 & 48.6 \\
Iron Chelating Agent (ICT) & & \\
Yes & 44 & 62.9 \\
No & 26 & 37.1 \\
Iron chelating agent prescribed (n= 44) & & \\
DFN only & 14 & 31.8 \\
DFO + DFN co-prescription & 14 & 31.8 \\
DFN \& DFX alternately & 2 & 4.5 \\
DFX only & 8 & 18.3 \\
DFO + DFX co-prescription & 6 & 13.6 \\
Splenectomy done & & \\
Yes & 4 & 5.7 \\
No & 66 & 94.3 \\
Can afford bone marrow transplantation & & \\
Yes & 0 & 0.0 \\
No & 70 & 100.0 \\
\hline
\end{tabular}

- ICT = Iron Chelating Therapy 
Out of 44 patients prescribed with different type ICT and combination, only $52.3 \%$ continued it for full prescribed period (Table II) Highest adherence was found to DFN (70\%) and lowest adherence was found to DFO (35\%) (Table II). The only cause of non-adherence to DFN and DFX was financial problem. The common causes of discontinuation of DFO were time consuming nature of parenteral infusion, financial problem and need of hospital admission for infusion (Table III).

Table II : Treatment profile and adherence of iron chelating therapy (ICT)

\begin{tabular}{|c|c|c|}
\hline Iron Chelating Therapy (ICT) & Frequency & Percentage $(\%)$ \\
\hline \multicolumn{3}{|l|}{ Adherence to ICT $(n=44)$} \\
\hline Full adherence & 23 & 52.3 \\
\hline Non-adherence & 21 & 47.7 \\
\hline \multicolumn{3}{|c|}{ Adherence of patients prescribed with only } \\
\hline \multicolumn{3}{|l|}{$\operatorname{DFN}(n=14)$} \\
\hline Continued & 10 & 71.4 \\
\hline Discontinued & 4 & 28.6 \\
\hline \multicolumn{3}{|c|}{ Adherence of patients prescribed with } \\
\hline \multicolumn{3}{|l|}{ DFO+DFN co-prescription $(n=14)$} \\
\hline Both continued & 5 & 35.7 \\
\hline DFN continued, DFO discontinued & 4 & 28.6 \\
\hline DFO continued, DFN discontinued & 0 & 0.0 \\
\hline Both discontinued & 5 & 35.7 \\
\hline \multicolumn{3}{|c|}{ Adherence of patients prescribed with DFN \& } \\
\hline \multicolumn{3}{|l|}{ DFX alternately ( $n=2)$} \\
\hline Both continued & 2 & 100.0 \\
\hline DFN continued, DFX discontinued & 0 & 0.0 \\
\hline DFX continued, DFN discontinued & 0 & 0.0 \\
\hline Both discontinued & 0 & 0.0 \\
\hline \multicolumn{3}{|c|}{ Adherence of patients prescribed with only } \\
\hline \multicolumn{3}{|l|}{$\operatorname{DFX}(\mathrm{n}=8)$} \\
\hline Continued & 4 & 50.0 \\
\hline Discontinued & 4 & 50.0 \\
\hline \multicolumn{3}{|c|}{ Adherence of patients prescribed with } \\
\hline \multicolumn{3}{|l|}{ DFO+DFX co-prescription $(n=6)$} \\
\hline Both continued & 2 & 33.3 \\
\hline DFX continued, DFO discontinued & 1 & 16.7 \\
\hline DFO continued, DFX discontinued & 0 & 0.0 \\
\hline Both discontinued & 3 & 50.0 \\
\hline \multicolumn{3}{|l|}{ Overall DFN adherence $(n=30)$} \\
\hline Continued & 21 & 70.0 \\
\hline Discontinued & 9 & 30.0 \\
\hline \multicolumn{3}{|l|}{ Overall DFX adherence $(n=16)$} \\
\hline Continued & 9 & 56.2 \\
\hline Discontinued & 7 & 43.8 \\
\hline \multicolumn{3}{|l|}{ Overall DFO adherence $(n=20)$} \\
\hline Continued & 7 & 35.0 \\
\hline Discontinued & 13 & 65.0 \\
\hline
\end{tabular}

- DFN = Deferiprone, DFX = Deferasirox, DFO = Desferrioxamine
Table III : Causes of non-adherence of iron chelating agents

\begin{tabular}{lcc} 
Cause of Non-adherence & Frequency & Percentage $\mathbf{( \% )}$ \\
Non-adherence to DFO $(\mathbf{n = 1 3})$ & & \\
Time consuming & 5 & 38.5 \\
Financial problem & 5 & 38.5 \\
Need admission & 3 & 23.0 \\
Not available & 0 & 0.0 \\
Forgetfulness & 0 & 0.0 \\
Non-adherence to DFN $(\mathbf{n}=\mathbf{9})$ & & \\
Financial problem & 9 & 100.0 \\
Not available & 0 & 0.0 \\
Forgetfulness & 0 & 0.0 \\
Non-adherence to DFX $(\mathbf{n}=\mathbf{7})$ & & \\
Financial problem & 7 & 100.0 \\
Not available & 0 & 0.0 \\
Forgetfulness & 0 & 0.0 \\
\hline
\end{tabular}

- $\mathrm{DFN}=$ Deferiprone, $\mathrm{DFX}=$ Deferasirox, $\mathrm{DFO}=$ Desferrioxamine

\section{DISCUSSION}

In our study, $25.7 \%$ patients need blood transfusion $<5$ unit per year, another $25.7 \%$ need $5-10$ unit year, $48.6 \%$ patients need up to $>10$ unit per year. Similarly, $23.7 \%$ received up to 5 unit/year, $29.66 \%$ up to $6-10$ unit/year, $30.4 \%$ received $11-15$ unit blood transfusion per year in a study of Mallik $\mathrm{S}$ et $\mathrm{al}^{22}$. We had only $5.7 \%$ splenectomized patient that is similar to that study $^{22}$. None was able to afford bone marrow transplantation but in Pakistan near about 5\% family were ready for bone marrow transplantation of their child ${ }^{23}$.

Monotherapy DFN (31.8\%) and combination of DFO \& DFN $(31.8 \%)$ were the highly prescribed drugs in our study. A worldwide survey reported that mono therapy with desferrioxamine (DFO) was the most widely used drug in the world and deferiprone (DFP) monotherapy and DFO \& DFP combination were more common in Europe and the MiddleEast/Africa than in the Asia-Pacific region ${ }^{24}$. In our study, $52.3 \%$ of our patients prescribed with ICT continued it for full prescribed period and highest adherence was found to DFN (70\%) and lowest to DFO (35\%). Lowest adherence to DFO also reported by Arif $\mathrm{F}$ et al and highest adherence to DFN by Kidson GL et $\mathrm{al}^{25,19}$. Compliance were unsatisfactory also in Srilanka ${ }^{26}$. Adherence rate was more better in North America where average adherence were $92.2 \%$ for DFO and $95.5 \%$ to oral chelator $(95.5 \%=\mathrm{DFX}, 94.5 \% \mathrm{DFN})$ and $76.1 \%$ of DFX and $87.8 \%$ of DFN showed at least $90 \%$ adherence respectively but in Australia majority showed $<50 \%$ adherence and a few $>90 \%$ adherence 27,19 . Higher adherence rate to DFN in our study may be due to low cost of DFN.

Similar to the reports of Olivieri NF et al, we found rate of nonadherence to ICT was highest for DFO (65\%) followed by DFX (43.8\%), DFN (30\%) $)^{28}$. Major cause of non-adherence to 
DFO was time consuming procedure $(38.5 \%)$ and financial problem $(38.5 \%)$ followed by cumbersome process that need hospital admission (23\%) suggesting along with financial problem mode of administration and need of hospital admission play a great role for adherence to DFO. Besides, financial problem was the only reason for discontinuation of DFN and DFX. In Australia financial problem was not an issue for non-adherence, too busyness of parents and discomfort of pump infusion reported as most common reason of DFO noncompliance ${ }^{19}$. An international survey reported that access to the drug was the most common cause of non-adherence in India $(51 \%)$, Iran $(25 \%)$ and other countries $(<17 \%)^{20}$. In some countries, false beliefs or feelings about the medication and drug related side effects is a common factor for noncompliance $^{19,20}$. In our study it is not a factor as we have a Thalassemia Care Center in our hospital for special care of thalassemia patients for which reason most of drugs needed to treat thalassemia patient are available at our hospital pharmacy. So oral ICT should be available free of cost at government setting as well as at NGO level.

\section{LIMITATIONS}

- This was a cross-sectional study where only 70 patients were included.

- Limited period of study for one year only.

- Data were collected only from one hospital.

\section{CONCLUSION}

Non-adherence to iron chelating drugs is quite common problem in our country. Cost of iron chelating drugs is the main reason for non-adherence followed by time consuming nature, need of hospital admission. Patient's concern for choosing drugs should be considered for better adherence especially in patients with poor socio-economic condition. As thalassemia is great health and economic burden to a family as well as to the society, health policy makers should take necessary step to make iron chelating drugs available at free of cost for improving the lives of patients.

\section{DISCLOSURE}

All the authors declared no competing interest. 


\section{REFERENCES}

1. Flint J, Harding RM, Boyce AJ, Clegg JB. The population genetics of the hemoglobinopathis. Ballier's Clinical Hematology. 1998;11:1-50.

2. Weatherall DJ. The global problem of genetic disease. Ann Hum Biol. 2005;32:117-122. doi: $10.1080 / 03014460500075480$.

3. WHO guidelines for control of hemoglobin disorders. Unpublished document WHO/HDP/HB/GL/94.

4. Khan WA. Thalassemia in Bangladesh. Dhaka Shishu (Child) Hospital Journal. 1999;15:42-44.

5. Pemde HP, Chandra J, Gupte D et al. Physical growth in children with transfusion dependent thalassemia. Pediatric Health, Medicine and Therapeutics. 2011;2:13-18.

6. Lesie A, Bogdanovic A, Sudjic V, Suvajdzic NV, Atkinson HDE, Bumbarirevic M. Thalassemia major: A report of two cases with severe skeletal involvement. ACI Vol. LVIII:99-102.

7. Karimi M, Emadmarvasti V, Hoseini J, Shoja L. Major causes of hospital admission in beta-thalassemia patients in Southern Iran. Iran J Pediatr. 2011;21(4):509-513.

8. Malik S, Syed S, Ahmed N. Complications in transfusion-dependent patients of beta-thalassemia major: A review. Pak J Med Sci. 2011;28(2):134-139.

9. Cunningham MJ, Macklin EA, Neufeld EJ, Cohen AR. Complication of beta-thalassemia major in North America. Blood. 2004;104(1):34-39.

10. De Sanctis V, Roos M, Gasser T, Fortini M, Raiola G, Galati MC. Impact of long-term therapy on growth and endocrine functions in thalassemia. J Pediatr Endocrinol. 2006;19(4):471-480.

11. Anggororini D, Fadlyana E, Idjradinata P. Correlation between serum feritin levels with delayed puberty in thalassemia major children. J of Indonesian Med Association. 2010;60(10):12-18.

12. Kurtoglu AU, Temizkan AK. Effect of iron overload on endocrinopathies in patients with beta-thalassemia major and intermedia. Endocrinopol. 2012;63(4):260-263.

13. Li C-K, Chik K-W, Lam C-W-K, To K-F, HYo S-C, Lee V et al. Liver disease in transfusion-dependent thalassemia major. Arch Dis Child. 2002;86:344-347.

14. Bazrgur M, Peirvian F, Abedpour F, Karimi M. Causes of hospitalization and death in Irarian patients with beta-thalassemia major. Pediatric Hematol Oncol. 2011;28(2):134-139.

15. Borgna P, Cappellini MD, Stefano De P et al. Survival and complication in thalassemia. Ann NY Acad Sci. 2005;1054:40-47.

16. Borgna $\mathrm{P}$, Rugolotto $\mathrm{S}$, De Stefano $\mathrm{P}$ et al. Survival and complication in patient with thalassemia major treated with deferrioxamine. Haematologica. 2004;89(10):1187-1193.

17. Olivieri NF, Brittenham GM. Iron chelating therapy and the treatment of thalassemia. Blood. 1997;89:739-761.

18. Vasilis G, Alexdra KS, Charalambos C. Comparative Effects of Three Iron Chelation Therapies on the Quality of Life of Greek Patients with Homozygoes Transfusion-Dependent Beta-Thalassemia. ISRN Hematol. 2012;2012:139862 (Published online Dec17, 2012). doi 10.5402/2012/139862.

19. Kidson GL, Francis S and Lindeman R. Management and clinical outcome of transfusion-dependent thalassemia major in an Australian tertiary referral clinic. Med J. 2008;188(2):72-75.

20. Ward A, Caro JJ, Green TC, Huybrechts K, Arama A, Wait S et al. An international survey of patients with thalassemia major and their views about sustaining life-long desferrioxamine use. BMC Clin Pharmacol. 2002;2:3 (Published on 23 April, 2002).

21. Scalone L, Mantovani LG, Krol M, Rofail D, Ravera S, Bisconte GB et al. Cost, quality of life, treatment satisfaction and compliance in patients with beta-thalassemia major undergoing iron chelation therapy -The ITHACA Study. Curr Med Res Opin. 2008;24(7):1905-1917.

22. Mallik S, Chatterjee C, Mandal PK, Sardar JC, Ghosh P and Manna N. Expenditure to treat thalassemia: An experience at a tertiary care hospital in India. Iran J Public Health. 2010;39(1):78-84.

23. Rahaman S, Batool S, Qadir R. Socio economic status impact thalassemia child on families of Faisalabad district. Pak J of Appl Sci. 2002;2(2):202-205.

24. Viprakasit V, Gattermann N and Cappellini MD. Geographical variations in current clinical practice on transfusion and iron chelation therapy across various transfusion-dependent anemia. Blood Transfus. 2013;11(1):108-122.

25. Arif F, Fayyaz J, Hamid A. Awareness among parents of children with thalassemia major. JPMA. 2008;58(11):621-624

26. Samarakoon PS and Nijesuriya AP. Thalassemia in Srilanka: Implications for future health of Asian population- Srilanka Thalassemia Study Group. Lancet. 2000;355:786-791.

27. Trachtenberg FL, Mednick L, Kwiactkowski JL, Neufeld E, D Haines D, Pakbaz Z et al. Belief about chelation among thalassemia patients Health and Quality of life Outcome. 2012;10:148.

http://www.hqlo.com/content/10/1/148 (Accepted on November 27, 2012).

28. Olivieri NF, Brittenham GM. Iron chelating therapy and the treatment of thalassemia. Blood. 1997;89:739-761. 